\title{
Strategies Used by Four Iranian EFL Learners in Reading ESP and GPE Texts:
}

\section{A Think-aloud Case Study}

\author{
Maryam Sadat Tabataba’ian \\ English Department, Ferdowsi University of Mashhad \\ P.O. Box 91779-48974, Park Square, Ferdowsi University Mashhad, Iran \\ Email: marytaba6@yahoo.com
}

Reza Zabihi (Corresponding author)

English Department, Ferdowsi University of Mashhad

P.O. Box 91779-48974, Park Square, Ferdowsi University Mashhad, Iran

Email: zabihi@hotmail.com

Received: February 15, $2011 \quad$ Accepted: March 21, $2011 \quad$ doi:10.5430/wjel.v1n1p53

\begin{abstract}
The case study reported in this paper was conducted to investigate the differences between strategies used in reading ESP and GPE texts using the think-aloud approach as a way of understanding the mental processes the subjects go through and also a method of eliciting the strategies used when they are performing a task. Four EFL learners studying in an upper-intermediate level at College of Ferdowsi University in Mashhad received a GPE (General Purpose English) text along with four ESP (English for Specific Purposes) texts. The data obtained were analyzed qualitatively. The strategies used by subjects were identified according to O’Malley and Chamot's (1990) model of language learning strategies. The results indicated that while cognitive strategies were used quite often in reading both types of texts, socioaffective strategies were not used at all. Moreover, some differences were observed between the types of cognitive and metacognitive strategies used by the subjects for reading ESP and GPE texts. It was revealed that drawing on background knowledge is done more often when learners read ESP texts. In addition, drawing on background knowledge and confirming the knowledge proved to be important strategies for reading ESP texts. Finally, the results of the study were discussed, implications of the findings were cited, and suggestions for future research were offered.
\end{abstract}

Keywords: Protocol analysis, Think-aloud method, Case study, Reading strategy use, ESP texts, GPE texts

\section{Introduction}

In their attempts to find out why some language learners are more successful than others, researchers began to uncover the characteristics of successful language learners. Part of this question can be dealt with by taking into account the different language learning strategies learners use for handling their problems in the learning process (Naiman, Frohlich, Stern, \& Todesco, 1976; Rubin, 1975; Stern, 1975). To this end, many scholars and researchers have tried to define and measure language learning strategies (e.g. Tarone, 1983; Cohen, 1998; O’Malley \& Chamot, 1990; Oxford, 1990).

Although the most popular way of identifying learning strategies is through administering questionnaires (see Oxford, 1990), it suffers from a major limitation: Memory loss. Learners may forget the strategies they have used in the past (Chamot, 2004). On the other hand, if learners verbalize their strategies while they are performing a task, little or no memory loss is likely to occur. Therefore, because these strategies are mostly unobservable in nature, we cannot find out whether learners are using a particular strategy unless we ask them (O’Malley \& Chamot, 1990; Wenden, 1991). Put it another way, the most reliable, and the only direct, way for the elicitation of learning strategies is through learners' verbal reports (Grenfell \& Harris, 1999) which is an on-line measure of reading comprehension (Graesser, Singer, \& Trabasso, 1994); otherwise we have to study them indirectly (Wade, 1990).

Cognitive scientists have developed performance measures such as think-aloud to infer cognitive processes. Although behaviorists denied mind and mental processes, introspection was revived with the growth of cognitive psychology (Ghonsooly, 1997). Think-aloud is a research method by which we, as researchers, can explore individuals' invisible cognitive processes. Many scholars have either considered or employed think-aloud approach as a powerful research 
method (e.g., Ericsson \& Simon, 1980; Ericsson \& Simon, 1993; Olson, Duffy, \& Mack, 1984; Sainsbury, 2003; Stevenson, Schoonen, \& Glopper, 2007), some researchers have pointed up the advantages of using think-aloud approaches for collecting information about individuals' strategy use (e.g., Garner, 1987; Henk, 1993; Pressley \& Afflerbach, 1995), and many researchers have suggested characteristics of suitable tasks for think-aloud studies (e.g., Akyel \& Kamisli, 1996; Ericsson \& Simon, 1980; Johnson, 1992; Charters, 2003).

Research has revealed that those learners who use a variety of different learning strategies are more successful language learners (Bruen, 2001; Green \& Oxford, 1995; O’Malley \& Chamot, 1990; Wharton, 2000). One major area of study in which think-aloud can be employed as a powerful method is the elicitation of learners' reading strategy use. Think-aloud method is a useful measure for the assessment of readers' comprehension during reading (Cakir, 2008). As Alderson and Urquhart (1984) argue, if the strategies that readers use are discovered, we may find general elements across different texts which can lead to reading improvement through teachers' focus on those strategies which readers use more frequently. To this end, the present case study investigates the frequency of different reading strategies English language learners use while reading ESP and GPE texts in the Iranian EFL context.

\section{Theoretical Background}

\subsection{The Think Aloud Technique}

Different performance measures for inferring cognitive processes have been developed by cognitive scientists. Think-aloud is an approach which focuses on immediate learning experience enabling participants to focus on what they are doing. Using this method, very detailed data in real-time use can be achieved (Cotton \& Gretsy, 2006). In thinking aloud, thoughts are said without an attempt on the readers' part to control, direct or observe them (Ghonsooly, 1997). As Ericsson and Simon (1980) state, the subjects' verbalizations as think-aloud data on thought processes are a "thoroughly reliable" source of information (p. 247). Moreover, due to its open-ended nature, think aloud is a promising method for activating metacognition; its purpose is to help develop the monitoring ability of second language learners and use strategies to help understanding of the text (McKeowon \& Gentilucci, 2007).

Protocol analysis, which is quite related to think-aloud, is a rigorous research method that requires research participants to verbalize their thoughts while performing a task (Cotton \& Gresty, 2006; Crutcher, 1994; Ericsson \& Simon, 1993; Van-Someren, Barnard, \& Sandberg, 1994) without changing the sequence of thoughts, making it a valid source of data on thinking (Ericsson, 2001). The verbal response is usually captured with a tape or video recorder, or by note taking (Cotton \& Gresty, 2006).

\subsection{Reading Comprehension}

A text does not carry meaning by itself; the reader brings information, knowledge, emotions and experiences to the printed word (Brown, 2001). According to Brown (2001), there are two categories of schemata: content schemata and formal schemata. The former refers to our knowledge of people, the world, culture and the universe, whereas the latter refers to our knowledge of the structure of texts.

Alderson and Bachman (2000) make a distinction between the process of reading and the result of that process, i.e. the product. The process refers to the interaction of the reader and the text, and what the reader can get as the meaning of a text. They further suggest that the process of reading is not a static process; rather it is a dynamic one. In the same vein, Nuttall (1996) maintains that reading, like conversation, is interactive; in other words, readers and writers depend on one another. Interactive reading in another sense refers to a continual shift from one focus to another, now adopting a top-down approach to predict the probable meaning, then moving to the bottom-up approach for checking that meaning.

Although Wades (1990) believes that top-down and bottom-up strategies, as the two categories of cognitive processing, encompass general comprehension strategies (as cited in Smith, 2006), Brown (2001), Ghonsooly (1997), and McCormick (1988) contend that three basic models of reading comprehension processes exist: bottom-up, top-down, and interactive. In the bottom-up approach, reading is assumed to be a passive process and there is no room for higher order processes (Celce-Murcia \& Olshtain, 2000; Van Dijk \& Kintsch, 1983). According to Mitchel (1982), this model lacks flexibility. In the top-down approach, reading is viewed as an active process in which the reader brings knowledge structures to the text (Anderson, Reynolds, Schallert \& Goetz, 1977). However, Eyskey (1986, as cited in Ghonsooly, 1997) criticizes this model for downplaying the importance of the text. Readers' over-reliance on top-down approach is due to their lack of ability to use strategies to monitor their comprehension of texts (Wade, 1990). Some authors (Alderson \& Bachman, 2000; Brown, 2001; Kendeou \& van den Broek, 2005; Rumelhart, 1997; Singer, 1990), therefore, suggest that both top-down and bottom-up processes are important, and a combination of these two processes, i.e., interactive reading, is necessary for reading successfully. In other words, it is impossible for us to get the meaning of 
what we read first and later on understand what the letters, words, and sentences which mediated the meaning were (Rumelhart, 1997).

Reading research adopts one of the two approaches: the psychometric approach and the cognitive approach. The former approach considers reading comprehension as comprising a number of sub-skills. The latter deals with exploring the way textual features interact with the readers’ processing system (Hills, 1988, as cited in Ghonsooly, 1997).

\subsection{Learning Strategies}

The term strategy should not be confused with skill as they are used to refer to two distinct processes. The terms skill and strategy are used to distinguish automatic processes from deliberately controlled processes; in other words, skill use is automatic but strategy use is controlled (Afflebach, Pearson, \& Paris, 2008).

Learning strategies are divided into three main categories: metacognitive, cognitive, and socioaffective (O’Malley \& Chamot, 1990). While learners use cognitive strategies to achieve a particular goal, say, understanding a text, metacognitive strategies are used to ensure that the reader has successfully done the activity after it is completed (Livingstone, 1997). Socioaffective strategies, on the other hand, deal with learners' interactions with others (Brown, 2000).

Previous research on learning strategies has revealed that those learners who use a variety of different learning strategies are more successful in language learning (Chamot \& El-Dinary, 1999; Green \& Oxford, 1995; O’Malley \& Chamot, 1990; Wharton, 2000).

As Chamot (2004) claims, a number of models for learning strategy instruction have been suggested many of which focus on learners' metacognitive awareness promoted by teachers' modeling of appropriate learning strategies.

\subsection{Reading Comprehension, Reading Strategies and Protocol Analysis}

Cognitive theory has become important in reading research literature since the 1970s. From the information processing perspective, reading includes a series of complex cognitive processes. Poor readers are deficient in multiple reading processes. Langer (1982, cited in Rao, Gu, Zhang, \& Hu, 2007) defines reading strategies as mental operations relating to how readers perceive a task, what textual cues they pay attention to, how they make sense of what they read, and what they do when they do not understand. Strategies are therefore reader's resources for understanding and learning. As Pressley (2000) and Wade (1990) put it, good readers apply a variety of appropriate strategies to the text they are reading. From the earliest stage children use strategies by drawing upon their existing knowledge and understanding to comprehend the text (Sainsbury, 2003).

The strategies can be improved by direct instruction (Lau, 2006). As Lau (2006) claims, good readers are those who use better strategies; poor readers either give up easily when they face problems or they use inefficient strategies.

As Ghonsooly (1997) states, the study of reading comprehension has been the focus of interospectionist researchers more than other skill. Alderson and Urquhart (1984) argue that if the strategies that the readers use are found out, we may find general elements across different texts which helps reading improvement. Then we can understand the successful and less successful readers' strategy use.

In using this method, a reading task is chosen and the subjects are asked to say aloud everything they think while performing the task. This method directly assesses subjects' strategy use; it also provides product information and process report, avoids problem of memory failure, and allows for analysis of affective and cognitive processes (Lau, 2006).

\section{Purpose of the Study}

Many studies have been done in ESP using the introspection technique some of which have compared the strategies of successful and unsuccessful readers (e.g., Hosenfeld, 1977). These studies have shown that there are differences between readers' strategy use. Cohen, Glasman, Rosenbaum-Cohen, Ferrara, and Fine (1979) pointed out the difficulties of students while reading ESP texts. Padron, Knight, and Waxman (1986) also examined to find out whether there is a difference between strategies of bilingual and monolingual students while reading. Moreover, Sarig (1987) studied the differences between reading processes of L1 and L2 to see if they are related to each other. Ghonsooly (1997) also used introspection to describe competence in reading skills. Although all these studies have worked on reading comprehension using the think aloud method, none has examined the differences between reading strategies while reading ESP and GPE texts. To the researchers' best knowledge, however, no study to date has compared different text genres (e.g., ESP and GPE) with respect to the reading strategies readers use. The present study thus aims at examining the differences between reading strategies utilized by readers while reading ESP and GPE texts by applying the think-aloud method based on O'Malley and Chamot's (1990) model of learning strategies. The study was thus 
conducted to answer the following question: Are there any differences between readers' strategy use while reading GPE and ESP texts?

\section{Method}

\subsection{Participants}

Four people were chosen in the present study as subjects, three males and one female. Their age ranged from 19 to 27. They were all studying English at College of Ferdowsi University in Mashhad, a city in north-eastern Iran, in an upper-intermediate level (Pre-FCE 2). They were chosen based on their performance on the FCE sample examination: Their proficiencies were nearly the same with slight differences and they were more proficient than their classmates. The subjects were studying in different majors at university: An MSc student in Mechanical Engineering, an MSc student in Industrial Management (his BSc was in Computer Sciences), a student graduated from Power Engineering, and a sophomore in Electrical Engineering.

\subsection{Instrumentation}

The think aloud technique was chosen so that the researchers could understand and elicit their reading strategy use. In this method there is no threat to memory loss and the subjects will report whatever goes on in their minds. A GPE text and four ESP texts (chosen based on their major) were given to the subjects. The subjects' reports on what went on in their minds were tape recorded and notes were also taken. Later on, the researchers compared the reports and transcribed the recordings. The GPE text and one of the ESP texts used in the present study are given in Table 1.

$$
<\text { Table } 1 \text { about here }>
$$

\subsection{Procedure}

\subsubsection{Data Collection}

The data collection was done in College of Ferdowsi University for three of the subjects and in Faculty of Letters and Humanities of Ferdowsi University for the other one. The researcher tried to control the distracters as much as possible.

Four ESP texts were chosen based on the subjects' majors and they were confirmed by experts in the respective majors. The texts were taken from SAMT specific English books for different majors. A GPE text (the same for all subjects) was also chosen by an expert with regard to the subjects' proficiency. This text was chosen from sample TOEFL tests.

Each subject was asked to read two texts: A GPE and an ESP text. They were asked to talk about whatever went on in their minds. The researchers tried to interfere as little as possible while trying to handle the research in a way that their presence was not felt by the subjects. The subjects' reports were then recorded. These recordings were later transcribed and analyzed.

\subsubsection{Data Analysis}

Having been transcribed, the data was analyzed using the O’Malley and Chamot's (1990) model of learning strategies. First, the strategies were identified for each utterance and then each utterance was checked out to see if there are any differences in strategy use while reading an ESP text and a GPE text.

\section{Results and Discussion}

As already stated, the strategies used by subjects were identified according to O’Malley and Chamot's (1990) model to see which strategies were used by the subjects while reading and if there were any differences between the strategies used. The uses of cognitive strategies for the GPE text are summarized in Table 2. As can be seen in this table, while Repetition was the most frequently used strategy in reading a GPE text (54.5\%), Deduction and Watcher's strategy were, among others, the least frequently used strategies (2.3\%). Forty four cognitive strategies in total were used by the subjects while reading GPE texts.

$<$ Table 2 about here>

Furthermore, the uses of metacognitive strategies for the GPE text are summarized in Table 3. As may be seen in the table, the total number of metacognitive strategies used by the subjects for reading the GPE text was 12 . Among these, Self-management and Self-monitoring comprised about $67 \%$ of all metacognitive strategies used. The subjects used Confirmation of background knowledge and Self-evaluation twice (16.6\%). Accordingly, Table 4 demonstrates part of a verbal protocol produced by a student of computer engineering while reading the GPE text.

\section{$<$ Tables 3 \& 4 about here $>$}

The uses of cognitive strategies for the ESP text are summarized in Table 5. As can be seen in this table, among the thirty-three cognitive strategies used by subjects while reading ESP texts, Repetition and Transfer encompass 25 
strategies (75.8\%). On the other hand, Deduction, Skipping, and Watcher's Strategy were not used at all (0\%). Finally, Translation and Inferencing were used 5 (15.2\%) and 3 (9\%) times, respectively.

\section{$<$ Table 5 about here $>$}

The uses of metacognitive strategies for the ESP text are summarized in Table 6. As may be seen in the table, a total of 11 metacognitive strategies were used by the subjects while reading ESP texts. Self-monitoring comprised over half of all metacognitive strategies used (54.5\%). Table 7 also shows part of a verbal protocol produced by a student of computer engineering while reading an ESP text.

$<$ Tables $6 \& 7$ about here>

However, there existed no socio-affective strategies in the subjects' reports; none of the participants reported them while reading any of the five texts used in this study.

The cognitive strategies were used more in both GPE and ESP texts; however, the types of cognitive and metacognitive strategies used in GPE and ESP texts were different. Having compared Table 2 and Table 5 (cognitive strategies), the researchers found out that repetition was the strategy used most often in reading both GPE and ESP texts. In other words, participants tended to reprocess many sentences while reading. Translation was also used similarly when dealing with GPE and ESP texts.

In addition, it was found that transfer was a strategy used more often while reading an ESP text than when reading a GPE text. Participants drew on their background knowledge while reading an ESP text much more than the time they were reading a GPE text. The difficulty of both texts were the same but the ESP text was evaluated much easier by the participants than the GPE text; they could understand the ESP text easier because of their background knowledge and because there were fewer unknown vocabularies as they were familiar with technical and semi-technical words.

On the other hand, Deduction, skipping and watcher's strategy proved to be the strategies which were not very common among the subjects in reading GPE texts and they were not used in reading ESP texts at all.

Having compared Table 3 and Table 6, the researchers found out that in reading GPE texts self-monitoring and self-management were the ones used more than the other strategies. In ESP texts, however, self-monitoring was the one used more often than the other strategies, whereas self-management was not used at all. Confirming background knowledge was used more while reading ESP texts than it was used in GPE texts.

As it was seen, the cognitive strategies are drew on more than metacognitive strategies in reading both ESP and GPE texts and there were differences in the specific type of strategy used by the participants.

\section{Conclusion}

This study points to different reading strategies of students with different texts. Specifically, this study examined the differences between strategy use in reading ESP and GPE texts making use of verbal protocols produced by the subjects. The findings of the present study can help teachers of ESP and GPE texts teach the strategies used related to the text they are teaching. Although the limited sample size in the present case study warrants caution in generalizing the results, the findings obtained in the particular learning situation can make teachers be aware of the important strategies that are used more frequently in reading and comprehending the texts they are teaching.

Although the strategies used seem to differ individually rather than across the texts, several patterns were observed. It was shown that drawing on background knowledge (referred to as transfer here) is done more often when people read ESP texts. Drawing on background knowledge and confirming background knowledge seem to be important strategies when reading ESP texts. As Kendeou \& van den Broek (2005) have stated, readers' background knowledge plays a very important role in their comprehension of scientific texts. If teachers help learners find the relationships between different concepts and the relevant background knowledge associated with those concepts, learners can become more strategic readers.

To bring the confines of the research within bounds amenable to study, however, certain delimitations had to be imposed on it. Firstly, the sample size was so small, so there may be some concerns regarding the generalizability of the findings. In addition, the limitations of the methodology (the think-aloud approach) are also the limitations of the present study. Finally, the presence of the researcher was also a limitation as the participants might not have engaged in the text as when they would normally do. Therefore, future studies may be conducted with a large sample, using a variety of instruments, and across different cultures, disciplines, and text genres; in this way, the results tend to be more reliable. A study can also be done to see if it is the individual differences or the differences among genres that account for different strategies used. Only then can we obtain a thorough picture of the interactions among readers, writers, and texts by considering the mediation of learning strategies. 


\section{References}

Afflebach, P., Pearson, P. D., \& Paris, S. G. (2008). Clarifying differences between reading skills and reading strategies. The Reading Teacher, 61(5), 364-373. doi:10.1598/RT.61.5.1, http://dx.doi.org/10.1598/RT.61.5.1.

Akyel, A. \& Kamisli, S. (1996). Composing in first and second languages: Possible effects of EFL writing instruction. Paper presented at the Balkan Conference on English Language Teaching of the International Association of Teachers of English as a Foreign Language, Istanbul, Turkey. (ERIC Document Reproduction Service No. ED 401 719)

Alderson, J., \& Bachman, F. (2000). Assessing reading. Cambridge: Cambridge University Press. doi:10.1017/CBO9780511732935, http://dx.doi.org/10.1017/CBO9780511732935.

Alderson, J. C., \& Urquhart, A. H. (eds) (1984). Reading in a foreign language. London: Longman.

Anderson, R. C., Reynolds, R. E., Schallert, D. L., \& Goetz, E. T. (1977). Frameworks for comprehending discourse. American Educational Research Journal, 14, 367-381.

Brown, H. D. (2000). Principles of language learning and teaching (Fourth Edition). New York: Longman.

Brown, H. (2001). Teaching by principles: An interactive approach to language pedagogy, $\left(2^{\text {nd }}\right.$ ed.). White Plains, NY: Pearson Education.

Bruen, J. (2001). Strategies for success: Profiling the effective learner of German. Foreign Language Annals, 34(3), 216-225. doi:10.1111/j.1944-9720.2001.tb02403.x, http://dx.doi.org/10.1111/j.1944-9720.2001.tb02403.x.

Cakir, O. (2008). The effect of textual differences on children's processing strategies. Reading Improvement. http://findarticles.com/p/articles/mi_hb6516/is_2_45/ai_n29452065/

Celce-Murcia, M., \& Olshtain, D. (2000). Discourse and context in language teaching: A guide for language teachers. Cambridge University Press.

Chamot, A. U. (2004). Issues in language learning strategy research and teaching. Electronic Journal of Foreign Language Teaching, 1(1), 14-26.

Chamot, A. U., \& El-Dinary, P. B. (1999). Children's learning strategies in immersion classrooms. The Modern Language Journal, 83(3), 319-341. doi:10.1111/0026-7902.00025, http://dx.doi.org/10.1111/0026-7902.00025.

Charters, E. (2003). The use of think-aloud methods in qualitative research: An introduction to think-aloud methods. Brock Education, 12(2), 68-82.

Cohen, A. D. (1998). Strategies in learning and using a second language. London: Longman.

Cohen, A., Glasman, H., Rosenbaum-Cohen, P., Ferrara, J., \& Fine, J. (1979). Reading for specialized purposes Discourse analysis and the use of student informants. TESOL Quarterly, 13 (4), 551-564. doi:10.2307/3586449, http://dx.doi.org/10.2307/3586449.

Cotton, D., \& Gresty K. (2006). Reflecting on the think-aloud method for evaluating e-learning. British Journal of Educational Technology, 37(1), 45-54. doi:10.1111/j.1467-8535.2005.00521.x, http://dx.doi.org/10.1111/j.1467-8535.2005.00521.x.

Crutcher, R. (1994). Telling what we know: The use of verbal report methodologies in psychological research. Psychological Science, 5, 241-244. doi:10.1111/j.1467-9280.1994.tb00619.x, http://dx.doi.org/10.1111/j.1467-9280.1994.tb00619.x.

Ericsson, K. A. (2001). Protocol analysis in psychology. In N. Smelser and P. Baltes (Eds.), International encyclopedia of the social and behavioral sciences (pp. 12256-12262). Oxford, UK: Elsevier.

Ericsson, K. A., \& Simon, H. A. (1980). Verbal reports as data. Psychological Review, 87(3), 215-251. doi:10.1037/0033-295X.87.3.215, http://dx.doi.org/10.1037/0033-295X.87.3.215.

Ericsson, K. A., \& Simon, H. A. (1993). Protocol analysis: Verbal reports as data. Cambridge, MA: MIT Press.

Garner, R. (1987). Metacognition and reading comprehension. Norwood, NJ: Ablex Publishing Co.

Ghonsooly, B. (1997). Introspection as a method of identifying and describing competence in reading skills, Doctoral dissertation, University of Stirling, UK, 1997. 
Graesser, A. C., Singer, M., \& Trabasso, T. (1994). Constructing inferences during narrative text comprehension. Psychological Review, 101, 371-395. doi:10.1037/0033-295X.101.3.371, http://dx.doi.org/10.1037/0033-295X.101.3.371.

Green, J.M., \& Oxford, R. (1995). A closer look at learning strategies, L2 proficiency, and gender. TESOL Quarterly, 29(2), 261-297. doi:10.2307/3587625, http://dx.doi.org/10.2307/3587625.

Grenfell, M., \& Harris, V. (1999). Modern languages and learning strategies: In theory and practice. London: Routledge.

Haghani, M. (2007). Special English for the students of computer. Iran: SAMT.

Henk, W. A. (1993). New directions in reading assessment. Reading and Writing Quarterly, 9, 103-119. doi:10.1080/1057356930090106, http://dx.doi.org/10.1080/1057356930090106.

Hosenfeld, C. (1977). A preliminary investigation of the reading strategies of successful and nonsuccessful second language learners. System, 5(2), 110-123. doi:10.1016/0346-251X(77)90087-2, http://dx.doi.org/10.1016/0346-251X(77)90087-2.

Johnson, K. E. (1992). Cognitive strategies and second language writers: A re-evaluation of sentence combining. Journal of Second Language Writing, 1(1), 61-75. doi:10.1016/1060-3743(92)90020-P, http://dx.doi.org/10.1016/1060-3743(92)90020-P.

Kendeou, P., \& van den Broek, P. (2005). The effects of readers' misconceptions on comprehension of scientific text. Journal of Educational Psychology, 97(2), 235-245. doi:10.1037/0022-0663.97.2.235, http://dx.doi.org/10.1037/0022-0663.97.2.235.

Lau, K. L. (2006). Reading strategy use between Chinese good and poor readers: A think-aloud study. Journal of Research in Reading, 29(4), 383-399. doi:10.1111/j.1467-9817.2006.00302.x, http://dx.doi.org/10.1111/j.1467-9817.2006.00302.x.

Livingstone, J. A. (1997). Metacognition: an overview. Available online at: http://www.gse.buffalo.edu/fas/sheell/cep564/Metacog.htm (accessed August 2003).

McCormick, T. W. (1988). Theories of reading in dialogue: An interdisciplinary study. University Press of America.

McKeowon, R.G., \& Gentilucci, J. L. (2007). Think-aloud strategy: metacognitive development and monitoring comprehension in the middle school second language classroom. Journal of Adolescent and Adult Literacy.

Mitchell, T. M. (1982). Generalization as search. Artificial Intelligence, 18(2), 203-226. doi:10.1016/0004-3702(82)90040-6, http://dx.doi.org/10.1016/0004-3702(82)90040-6.

Naiman, N., Frohlich, M., Stern, H. H. \& Todesco, A. (1976). The good language learner. Research in Education Series No. 7. Toronto: The Ontario Institute for Studies in Education.

Nuttall, C. (1996). Teaching reading skills in a foreign language ( $2^{\text {nd }}$ Ed.). Oxford: Heinemann.

Olson, G. J., Duffy, S.A., \& Mack, R. L. (1984). Thinking-out-loud as a method for studying real time comprehension processes. In D.E. Kieras \& M.A. Just (Eds.), New methods in reading comprehension research (pp. 253-286). Hillsdale, NJ: Erlbaum.

O'Malley, J. M., \& Chamot, A. U. (1990). Learning strategies in second language acquisition. Cambridge: Cambridge University Press.

Oxford, R. L. (1990). Language learning strategies: What every teacher should know. New York: Newbury House.

Padron, Y., Knight, S., \& Waxman, H. (1986). Analyzing bilingual and monolingual students' perceptions of their reading strategies. The Reading Teacher, 39, 430-433.

Pressley, M. (2000). What should comprehension instruction be the instruction of? In M.L. Kamil, P.B. Mosenthal, P.D. Pearson, \& R. Barr (Eds.), Handbook of reading research: Volume III (pp. 545-561). Mahwah NJ: Erlbaum.

Pressley, M., \& Afflerbach, P. (1995). Verbal Protocols of Reading: The nature of constructively responsive reading. Hillsdale, NJ: Erlbaum.

Rao, Z., Gu, P.Y., Zhang, L.J., \& Hu, G. (2007). Reading strategies and approaches to learning of bilingual primary school pupils. Language Awareness, 16(4), 243-262. doi:10.2167/la423.0, http://dx.doi.org/10.2167/la423.0.

Rubin, J. (1975). What the "good language learner" can teach us. TESOL Quarterly, 9, 41-51. doi:10.2307/3586011, http://dx.doi.org/10.2307/3586011. 
Rumelhart, D. E. (1997). The architecture of mind: A connectionist approach. Mass.: MIT Press.

Sainsbury, M. (2003). Thinking aloud: children’s interactions with text. Reading Literacy and Language, November, 131-135.

Sarig, (1987). High-level reading in the first and in the foreign language: Some comparative process data. In Joanne Devine, P. L. Carrell, and D. E. Eskey (Eds.), Research in reading in English as a second language (pp. 105-120). TESOL: Washington.

Sharpe, P. J. (2004). How to prepare for the TOEFL test: Test of English as a foreign language. USA: Barron's Educational Series, Inc.

Singer, M. (1990). Psychology of language. New Jersey: Lawrence Erlbaum Associates.

Smith, L. A. (2006). Think-aloud mysteries: Using structured, sentence-by-sentence text passages to teach comprehension strategies. Reading Teacher, 59(8), 764-773. Retrieved July 31, 2006, from ERIC database. doi:10.1598/RT.59.8.4, http://dx.doi.org/10.1598/RT.59.8.4.

Stern, H. H. (1975). What can we learn from the good language learner? Canadian Modern Language Review, 31, 304-318.

Stevenson, M., Schoonen, R., \& Glopper, K. (2007). Inhibition or compensation? A multidimensional comparison of reading processes in Dutch and English. Language Learning, 57, 115-154. doi:10.1111/j.1467-9922.2007.00414.x, http://dx.doi.org/10.1111/j.1467-9922.2007.00414.x.

Tarone, E. (1983). Some thoughts on the notion of "communication strategy." In C. Faerch \& G. Kasper (Eds.), Strategies in interlanguage communication (pp. 61-74). London: Longman.

Van Dijk, T. A., \& Kintsch, W. (1983). Strategies of discourse comprehension. New York: Academic Press.

VanSomeren, M. W., Barnard, Y.F., \& Sandberg, J.A.C. (1994). The think aloud method: A practical guide to modeling cognitive processes. London: Academic Press.

Wade, S. E. (1990). Using think alouds to assess comprehension. The Reading Teacher, 43(7), 442-451.

Wenden, A. L. (1991). Learner strategies for learner autonomy. London: Prentice-Hall International.

Wharton, G. (2000). Language learning strategy use of bilingual foreign language learners in Singapore. Language Learning, 50(2), 203-244. doi:10.1111/0023-8333.00117, http://dx.doi.org/10.1111/0023-8333.00117.

Table 1. The GPE text and one of the ESP texts used in the study

\begin{tabular}{|l|l|}
\hline 1 & The GPE text used for all four subjects \\
\hline & $\begin{array}{l}\text { "Alfred Bernard Nobel, a Swedish inventor and philanthropist, bequeathed most of his vast fortune to a trust that he } \\
\text { achieved through invention or discovery that which would have the greatest benefit to humanity in a particular year. } \\
\text { According to the legend, Nobel's death had been erroneously reported in a newspaper, and the focus of the obituary } \\
\text { was the fact that Nobel had invented dynamite. He rewrote his will in 1895, thereby establishing, with the original } \\
\text { amount of nine million dollars, the Nobel Foundation as the legal owner and administering agent of the funds, and } \\
\text { instituting the prizes that are named after him. Statutes to govern the awarding of the prizes were written, along } \\
\text { with guidelines for operating procedures. Five years after Nobel's death, the first five prizes, worth about forty } \\
\text { thousand dollars each, were to be awarded" (Sharpe, 2004). }\end{array}$ \\
\hline $\mathbf{2}$ & $\begin{array}{l}\text { One of the four ESP texts used } \\
\text { "A variety of terminals enable both input and output from a remote computer system. Interactions via a terminal } \\
\text { outlets. } \\
\text { Dumb and Smart Terminals } \\
\text { Terminals come in all shapes and sizes and have a variety of input/output capabilities. The most popular } \\
\text { general-purpose terminal is the traditional video display terminal (VDT) that you see in hospitals and airports. The } \\
\text { primary input mechanism on the VDT, or simply the terminal, is a keyboard. Output is displayed on a monitor. Most }\end{array}$ \\
\hline
\end{tabular}


of these terminals are dumb; that is, they have little or no intelligence (processing capability). Typically, they provide text-only output (no graphics).

Some terminals, called windows terminals, have processing capabilities and RAM comparable to some PCs; however, they are not designed for stand-alone operation. The windows terminal is so named because the user interacts with a Windows 9x/NT/2000 graphical user interface (GUI). All Windows terminals are configured with some type of point-and-draw device, such as a mouse, to permit efficient interaction with the GUI" (Haghani, 2007).

Table 2. The uses of cognitive strategies for the GPE text

\begin{tabular}{|l|c|c|}
\hline Cognitive Strategies & Frequency & Percentage \\
\hline Repetition & 24 & $54.5 \%$ \\
\hline Transfer & 6 & $13.6 \%$ \\
\hline Translation & 7 & $16 \%$ \\
\hline Inferencing & 3 & $6.8 \%$ \\
\hline Deduction & 1 & $2.3 \%$ \\
\hline Skipping & 2 & $4.5 \%$ \\
\hline Watcher's Strategy & 1 & $2.3 \%$ \\
\hline Total & 44 & $100 \%$ \\
\hline
\end{tabular}

Table 3. The uses of metacognitive strategies for the GPE text

\begin{tabular}{|l|c|c|}
\hline Metacognitive Strategies & Frequency & Percentage \\
\hline Self-Management & 4 & $33.4 \%$ \\
\hline Confirmation of Background Knowledge & 2 & $16.6 \%$ \\
\hline Self-Monitoring & 4 & $33.4 \%$ \\
\hline Self-Evaluation & 2 & $16.6 \%$ \\
\hline Total & 12 & $100 \%$ \\
\hline
\end{tabular}

Table 4. Part of a protocol produced by one of the subjects while reading the GPE text and the identified strategies

\begin{tabular}{|l|l|l|}
\hline & Verbal reports & Identified reading strategy \\
\hline $\mathbf{1}$ & It made me think of Nobel. & Background knowledge activation \\
\hline $\mathbf{2}$ & Nobel prize & Background knowledge activation \\
\hline $\mathbf{3}$ & I do not know the meaning of 'Philanthropist'. & Failure at word level \\
\hline $\mathbf{4}$ & $\begin{array}{l}\text { I knew the meaning of 'designate' yesterday, but I do not } \\
\text { remember it now. }\end{array}$ & $\begin{array}{l}\text { Activating background knowledge/ failure at } \\
\text { word level }\end{array}$ \\
\hline $\mathbf{5}$ & A sound outside distracts me. & Distracter identification \\
\hline $\mathbf{6}$ & He is the same Nobel who invented dynamite. & Confirming background knowledge \\
\hline $\mathbf{7}$ & I finished the text, but I have to read it again. & Reprocessing to get the whole text \\
\hline $\mathbf{8}$ & I almost understand the meaning. & Partial confirmation of sentence meaning \\
\hline $\mathbf{9}$ & 'Nobel Foundation' is with capital letters. & Decoding \\
\hline $\mathbf{1 0}$ & It is probably the name of a company. & Guessing word meaning \\
\hline $\mathbf{1 1}$ & I wonder if I am doing what I am supposed to. & Conscious focus on task \\
\hline $\mathbf{1 2}$ & Because it is too long ... & Problem identification: length of sentence \\
\hline
\end{tabular}


Table 5. The uses of cognitive strategies for ESP texts

\begin{tabular}{|l|c|c|}
\hline Cognitive Strategies & Frequency & Percentage \\
\hline Repetition & 14 & $42.5 \%$ \\
\hline Transfer & 11 & $33.3 \%$ \\
\hline Translation & 5 & $15.2 \%$ \\
\hline Inferencing & 3 & $9 \%$ \\
\hline Deduction & 0 & $0 \%$ \\
\hline Skipping & 0 & $0 \%$ \\
\hline Watcher's Strategy & 0 & $0 \%$ \\
\hline Total & 33 & $100 \%$ \\
\hline
\end{tabular}

Table 6. The uses of metacognitive strategies for ESP texts

\begin{tabular}{|l|c|c|}
\hline Metacognitive Strategies & Frequency & Percentage \\
\hline Self-Management & 0 & $0 \%$ \\
\hline Confirmation of Background Knowledge & 3 & $27.3 \%$ \\
\hline Self-Monitoring & 6 & $54.5 \%$ \\
\hline Self-Evaluation & 2 & $18.2 \%$ \\
\hline Total & 11 & $100 \%$ \\
\hline
\end{tabular}

Table 7. Part of a protocol produced by one of the subjects while reading the ESP text and the identified strategies

\begin{tabular}{|c|l|l|}
\hline & Verbal reports & Identified reading strategy \\
\hline $\mathbf{1}$ & I hated computer engineering from the outset. & Background knowledge activation \\
\hline $\mathbf{2}$ & In the first sentence 'terminal' is used its usual meaning. & Confirmation of sentence meaning \\
\hline $\mathbf{3}$ & Somebody is snapping outside. & Distracter identification \\
\hline $\mathbf{4}$ & POS ... point-of-sail & Background knowledge activation \\
\hline $\mathbf{5}$ & I should read the last one again. & Sentence reprocessing \\
\hline $\mathbf{6}$ & I think I now understand what it says. & Confirmation of sentence meaning \\
\hline $\mathbf{7}$ & 'Dumb' probably means 'stupid' & Guessing word meaning \\
\hline $\mathbf{8}$ & 'Terminal' makes me think of Steven Spielberg's film. & Background knowledge activation \\
\hline $\mathbf{9}$ & I have never heard of 'video display terminal'. & Failure at word level \\
\hline $\mathbf{1 0}$ & The word 'stand-alone' is very familiar, but ... & Background knowledge activation/ failure at \\
\hline $\mathbf{1 1}$ & 'Point and draw' is like 'drag and drop'. & Background knowledge activation \\
\hline
\end{tabular}

